\title{
Power Quality Impact of Wind Farms on Domestic and Industrial Facilities
}

\author{
F. Oliveira ${ }^{1}$, A. Madureira ${ }^{2}$ and M. Pérez Donsión ${ }^{3}$ \\ ${ }^{1}$ Department of Electrical Engineering, E.S.T.G., Polytechnic Institute of Leiria \\ Morro do Leno - Alto Vieiro, Apartado 4163, 2411-901 Leiria, Portugal \\ Phone:+351 244 820300, Fax:+351 244 820310, E-mail: ftadeu@estg.ipleiria.pt \\ ${ }^{2}$ Power Systems Unit of INESC Porto \\ Rua Dr. Roberto Frias, 378, 4200-465 Porto, Portugal \\ Phone:+351 22 2094000, Fax:+ 35122 2094050, E-mail: agm@inescporto.pt \\ ${ }^{3}$ Department of Electrical Engineering, E.T.S.I.I., University of Vigo \\ Campus of Lagoas - Marcosende, 36310 Vigo, Spain \\ Phone:+34 986 812685, Fax:+34 986 812601, E-mail: donsion@uvigo.es
}

\begin{abstract}
The objective of this paper is to evaluate the impact of a nearby Wind Farm on Power Quality at local domestic and industrial facilities. Adequate, specialized measuring equipment made it possible to measure several quantities and assess the main Power Quality parameters with special incidence on Flicker and Harmonics levels.
\end{abstract}

\section{Keywords}

Power Quality, Flicker, Harmonics, Wind Farms

\section{Introduction}

The growth in the penetration of Renewable Energies in the Power Systems has been fast during the past few years and is expected to rise even more in the near future.

Wind generation in particular has been fast growing worldwide and the issue of the impact of the connection of wind generators to the main power grid is being thoroughly analysed by experts and investigators across Europe. The main concerns are related to the irregular behaviour of the primary power source (i.e. the wind) that has a deep impact on the quality of the electrical power generated by the wind turbines.

In this context, a thorough assessment of power quality from wind generators can provide valuable data and generate knowledge of the behaviour and impact of this type of generating devices. There are several technologies of measuring devices that have been developed recently. Two distinct types of measuring equipments with different characteristics were used to collect data on power quality parameters for this measuring campaign.

\section{Field Measurements}

As mentioned, this measurement campaign aimed at evaluating the impact on power quality of the electrical supply on the domestic and industrial facilities located in the proximity of the Monte Carrio Wind Farm located in the region of Pontevedra, Galicia, Spain.
The Monte Carrio Wind Farm comprises a total 37 wind turbines, each one with $850 \mathrm{~kW}$, with a total of 31.45 MW of installed capacity. The company running the wind farm is Sistemas Energéticos de Lalín, S.A.

The measuring campaign took place over a total period of approximately three weeks, at three measuring sites that were carefully chosen given the nature of each one.

The careful selection of measurement sites intended to include the various types of consumers, namely the domestic and the industrial ones. Hence, the sites chosen to host the measurement equipments were a sawmill, a restaurant and a domestic residence, all of them in the vicinities of the Monte Carrio Wind Farm.

The measuring equipments used were two 'MEMOBOX 300 smart' units from LEM and one 'Unilyzer 812' unit from UNIPOWER. Both types of units are capable of measuring several power quality parameters. The two types of equipment have a few differences related to the parameters that they are able to measure.

\section{Power Quality Analysis}

In face of the large amount of data available, a preliminary graphical analysis was made. The several power quality parameters were then analysed separately and observed with more attention.

The two most interesting results obtained were at the sawmill and the restaurant. Therefore, a detailed analysis of the data collected at these two sites will be made here. As for the domestic residence, only the main conclusions will be presented.

\section{A. Power Quality at the Sawmill}

A first measurement equipment was installed in a sawmill, where there were several significant electrical equipments (mostly motors) for sawing and preparing wood.

A table summarizing the main power quality parameters, the measured values and the standard values (according 
to the EN 50160 standard) for the sawmill is shown in table I.

Harmonics present relatively small values, as can be seen in figures 1 and 2 by the aggregate European THD values. Still, dominant harmonics are the usual $3^{\text {rd }}, 5^{\text {th }}$ and $7^{\text {th }}$ harmonics.

The three phases appear balanced with similar flicker values in all phases. The flicker is definitely the most delicate issue as it highly surpasses the limits set by the standard. This can also be observed in figures 1 and 2 .

A quick look at figure 1 provides unequivocal clues to the origin of flicker values there encountered. Flicker seems to have a "daily routine" as it starts to have significant values at about 8 a.m. every weekday morning, stops for lunch at about 1 p.m., resumes at 2 and finally decreases at about 7:30 p.m.. Weekends are clearly rest days as flicker values are comparable to night values on weekdays.

This clearly shows flicker values are strictly linked to the working hours of the facility.

Also, an extraordinary set of events occurred during the measuring period, most of them consisting of voltage dips, mainly between $10 \%$ and $15 \%$ of the nominal voltage, and with durations under $20 \mathrm{~ms}$.

\section{B. Power Quality at the Restaurant}

The second measurement site was a restaurant with few more than domestic electrical equipments. All significant cooking devices, such as the main stove, work on propane gas. Problems with TV signal reception were reported in the restaurant itself and in several residences nearby.

A summary of the main power quality parameters, the measured values and the standard values for the restaurant is shown in table II.

Figure 3 shows an interesting overview of the measurement campaign in this particular site. It shows the cumulative frequencies of harmonics, European total harmonic distortion (THD), short-term flicker $\left(\mathrm{P}_{\mathrm{st}}\right)$ and voltage unbalance levels. Most values are similar in the three phases, but oddly enough, phase one has higher flicker levels when compared to the other two, as can also be observed in figures 4 and 5 .

Flicker levels in all phases are high above the reference values set by the applicable standards. Contrary to what happened at the previous measurement site, flicker levels here cannot be easily linked to restaurant activity or working hours.

Also, dominant harmonics $3^{\text {rd }}, 5^{\text {th }}, 7^{\text {th }}$ and $9^{\text {th }}$ have relatively small values, as shown in figure 6. Voltage unbalance is quite low and within the admissible normative values, despite the "flicker unbalance".
As in the previous case, several events have been registered; mostly voltage dips between 10 and $15 \%$ of the nominal voltage of short duration $(<20 \mathrm{~ms})$. The great majority of these events were recorded in phase two, which was both intriguing and disturbing to the authors.

\section{Power Quality at the Domestic Residence}

Several measures were also obtained at a house located in the same geographical area. Electrical devices there installed were few and of small power consumption.

Once again, harmonic levels were not significant, as they are well below the levels set by the EN 50160 . Voltage unbalance was undeterminable as it consisted of a onephase supply.

Flicker levels are somewhat above those set by the standard. Figure 7 depicts some power quality parameters, highlighting an unusually high value of flicker registered shortly after a 100\% voltage dip.

\section{Conclusions}

Data collected at the three measurement sites revealed not very significant levels of harmonics, all of which well within the limits set by the EN 50160 standard.

However, flicker levels at any of the measuring sites exceed significantly the limits set by the standard, with different probable causes.

At the sawmill the flicker levels suggest "internal causes", i.e. flicker is caused by electrical equipments at the site and not so much by the nearby wind farm. This can be observed taking into account the low flicker levels at night time.

At the restaurant the flicker levels are most likely due to "external causes", either the nature of the grid or the nearby wind farm, since there seems to be no "internal causes" that can explain the high levels of flicker.

At the domestic residence, the flicker levels are also above the limit given by the standard and the possible origins are the same as in the restaurant.

On balance, all data collected suggest that flicker levels detected in the facilities may have different or even combined causes. A comprehensive study of the local electrical network characteristics, as well as field measurements at the wind farm itself, may provide additional clues to the real sources of the problem.

\section{Acknowledgement}

The authors wish to thank the support from the "Ministerio de Ciencia y Tecnología”, DPI2002-04416C04-02 project and "Xunta de Galicia”, PGIDIT03PXIC30308PN project. 


\section{References}

[1] F. Oliveira, A. Madureira and M. P. Donsión, "Experimental Study of Power Quality in Wind Farms", in ICREPQ’04, March 2004.

[2] M. Sanz et al, "Power Quality Measurements and Analysis for Wind Turbines”, in IMTC 2000, May 2000.

[3] T. Thiringer, "Power Quality Measurements Performed on a Low-Voltage Grid Equipped with Two Wind Turbines", in IEEE Transactions on Energy Conversion, Vol. 11, No 3, September 1996.

[4] T. Thiringer, T. Petru, C. Liljegren, "Power Quality Impact of a Sea Located Hybrid Wind Park", in IEEE Transactions on Energy Conversion, Vol. 16, No 2, June 2001. 
Table I - Table summary for the sawmill

\begin{tabular}{|c|c|c|c|c|c|c|c|c|}
\hline \multicolumn{3}{|c|}{ Parameter } & \multicolumn{3}{|c|}{ Maximum value } & \multicolumn{3}{|c|}{$95 \%$-value } \\
\hline & Unit & Default GWD.GWD & L1 & L2 & L3 & L1 & L2 & L3 \\
\hline Voltage variations & & $230.00 \mathrm{~V}$ & & & & & & \\
\hline Maximum $100 \%$ / 95\% & $\%[\mathrm{Un}]$ & $+10.00 /+10.00$ & 4.85 & 4.68 & 5.28 & 3.30 & 3.72 & 4.22 \\
\hline Minimum 100\% / 95\% & $\%$ [Un] & $-15.00 /-10.00$ & -4.91 & -4.76 & -4.67 & -3.30 & -3.72 & -4.22 \\
\hline Interruptions < $1 \%$ & Number of & 100 & 6 & 6 & 6 & & - & \\
\hline Events & Number of & 100 & $07=2487$ & 425 & 258 & & - & \\
\hline \multicolumn{9}{|l|}{ Harmonics } \\
\hline 5. Harm. & $\%[\mathrm{Un}]$ & 6.00 & 3.91 & 3.50 & 3.57 & 3.05 & 2.76 & 2.96 \\
\hline Flicker Plt & PIt & 1.000 & D1.769) & 1.827 & 1.838 & 1.557 & $\sqrt{1.608}$ & 1.599 \\
\hline Unbalance & $\%$ & 2.00 & \multicolumn{3}{|c|}{0.61} & \multicolumn{3}{|c|}{0.52} \\
\hline Signallingvoltages & $\%[\mathrm{Un}]$ & & \multicolumn{3}{|c|}{ No } & & & \\
\hline frequency & & $50 \mathrm{~Hz}$ & & & & \multicolumn{3}{|c|}{$99.5 \%$-value } \\
\hline Maximum $100 \%$ / $99.5 \%$ & $\%$ & $+4 /+1$ & \multicolumn{3}{|c|}{0.20} & \multicolumn{3}{|c|}{0.20} \\
\hline Minimum $100 \%$ / $99.5 \%$ & $\%$ & $-6 /-1$ & \multicolumn{3}{|c|}{-0.20} & \multicolumn{3}{|c|}{-0.20} \\
\hline
\end{tabular}

\section{[IIIIIIIIIIIIIA Max value above limit value}

DIMTMIMIMIIV $95 \%$ (99.5\%) - value above limit value

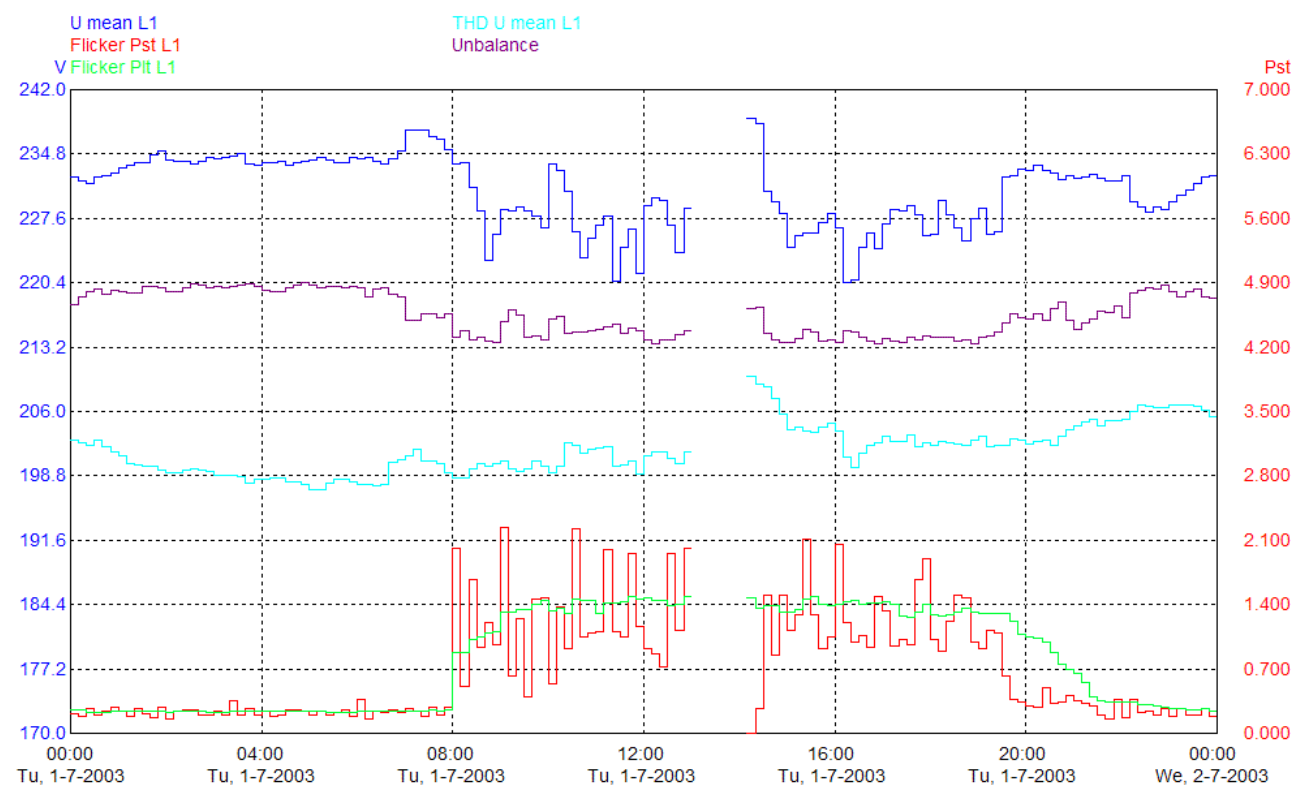

Fig. 1. Several power quality parameters measured at the sawmill over 1 day

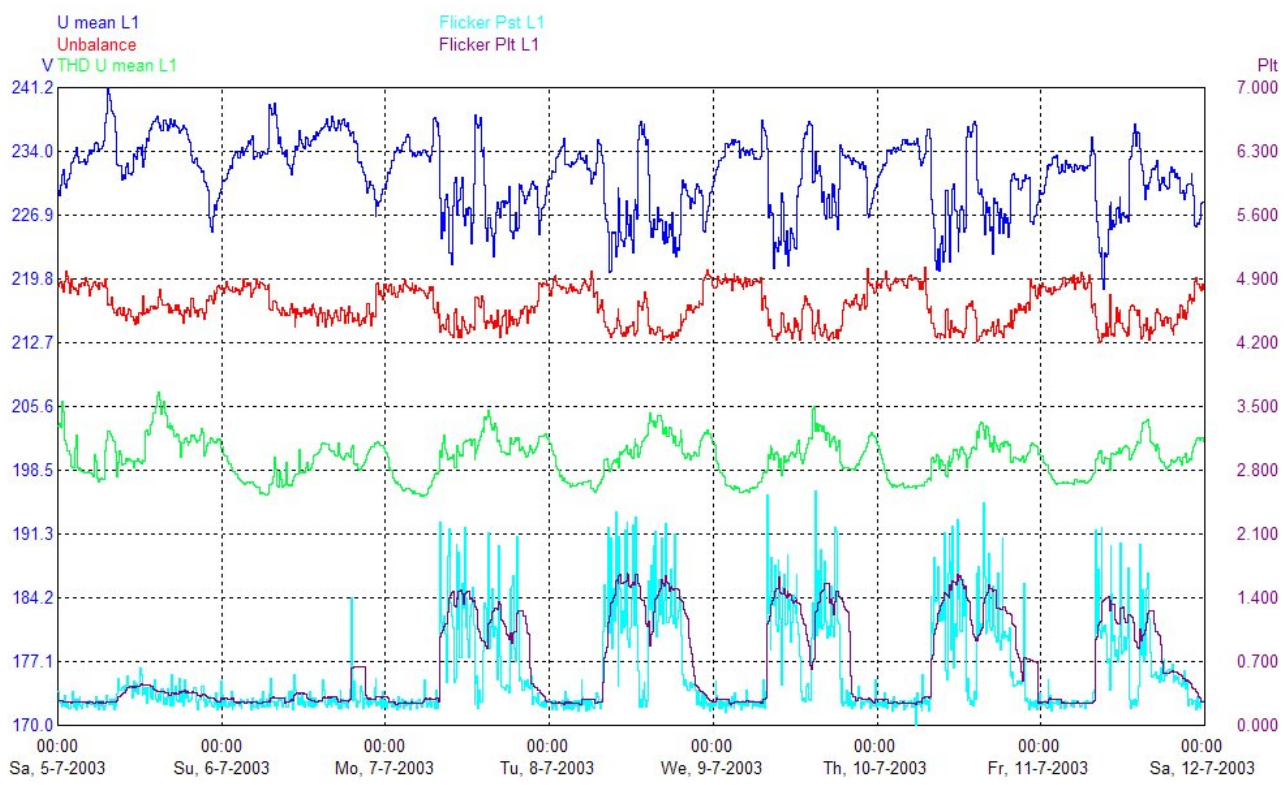

Fig. 2. Several power quality parameters measured at the sawmill over 1 week 
Table II - Table summary for the restaurant

\begin{tabular}{|c|c|c|c|c|c|c|c|c|}
\hline \multicolumn{3}{|c|}{ Parameter } & \multicolumn{3}{|c|}{ Maximum value } & \multicolumn{3}{|c|}{$95 \%$-value } \\
\hline & Unit & Default GWD.GWD & L1 & L2 & L3 & L1 & L2 & L3 \\
\hline Voltage variations & & $230.00 \mathrm{~V}$ & & & & & & \\
\hline Maximum 100\% / 95\% & $\%[$ Un] & $+10.00 /+10.00$ & 3.27 & 2.82 & 3.54 & 3.27 & 2.82 & 3.54 \\
\hline Minimum $100 \%$ / $95 \%$ & $\%[$ Un] & $-15.00 /-10.00$ & -6.76 & -9.11 & -7.42 & -3.92 & -5.47 & -5.12 \\
\hline Interruptions < $1 \%$ & Number of & 100 & 0 & 0 & 0 & & - & \\
\hline Events & Number of & 100 & 77 & UVI1982) & XVI111 & & - & \\
\hline \multicolumn{9}{|l|}{ Harmonics } \\
\hline 5. Harm. & $\%[$ Un] & 6.00 & 2.80 & 2.49 & 2.79 & 2.26 & 2.16 & 2.15 \\
\hline Flicker Plt & Plt & 1.000 & 3.315 & 1.853 & 1.625 & 2.619 & 1.260 & 1.121 \\
\hline Unbalance & $\%$ & 2.00 & & 1.11 & & & 0.79 & \\
\hline Signallingvoltages & $\%[$ Un] & & & No & & & & \\
\hline frequency & & $50 \mathrm{~Hz}$ & & & & & $9.5 \%$-va & \\
\hline Maximum 100\% / 99.5\% & $\%$ & $+4 /+1$ & & 0.20 & & & 0.20 & \\
\hline Minimum 100\% / 99.5\% & $\%$ & $-6 /-1$ & & -0.40 & & & -0.20 & \\
\hline
\end{tabular}

QIIIIIIIIIIIIIID Max value above limit value

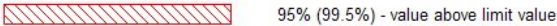
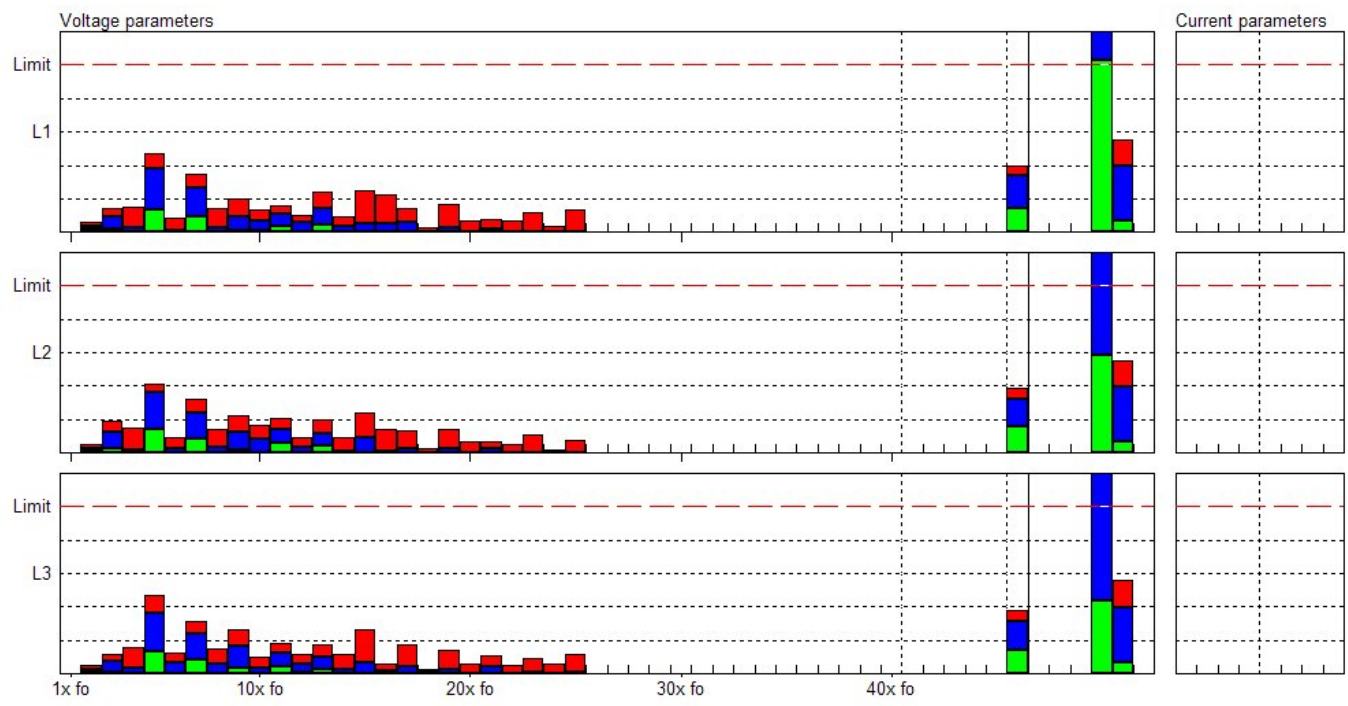

Fig. 3. Harmonics, THD, flicker $\mathrm{P}_{\mathrm{st}}$ and unbalance cumulative frequencies measured at the restaurant

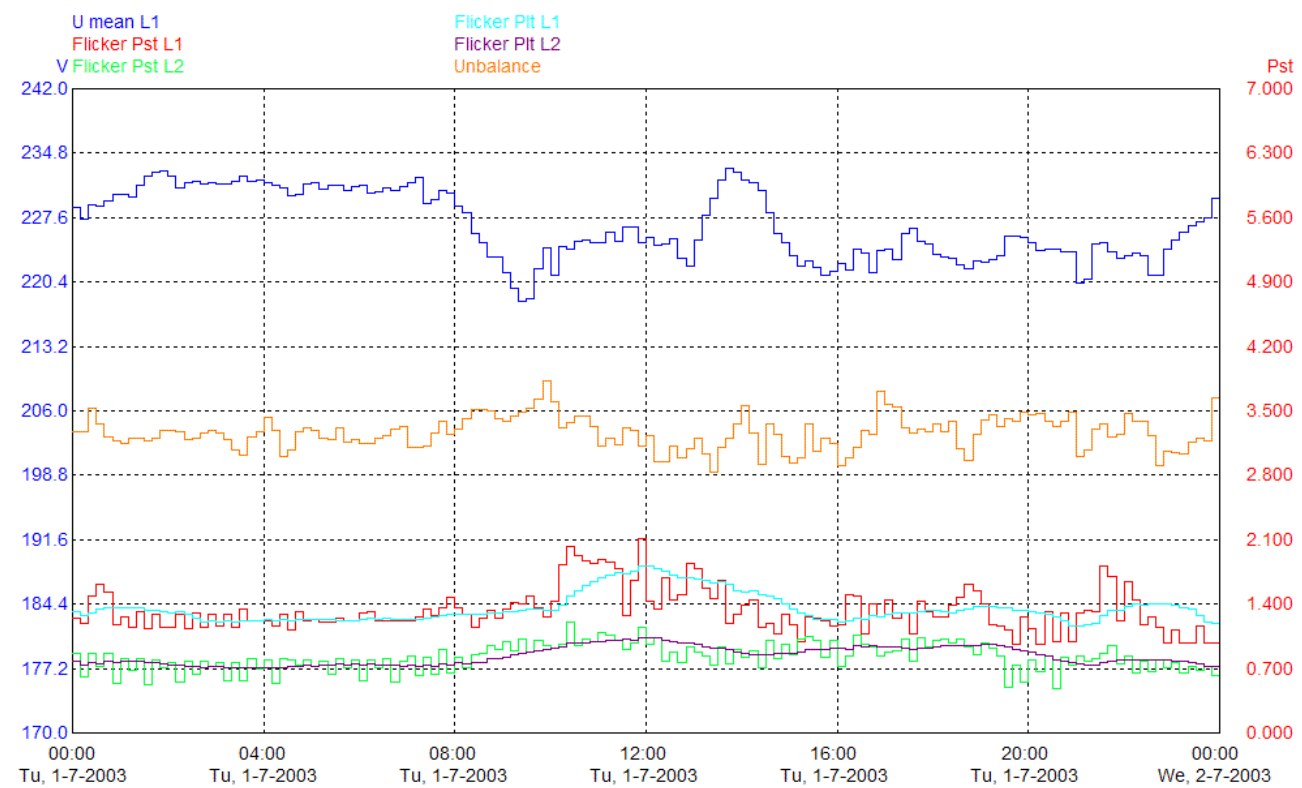

Fig. 4. Several power quality parameters measured at the restaurant over 1 day 


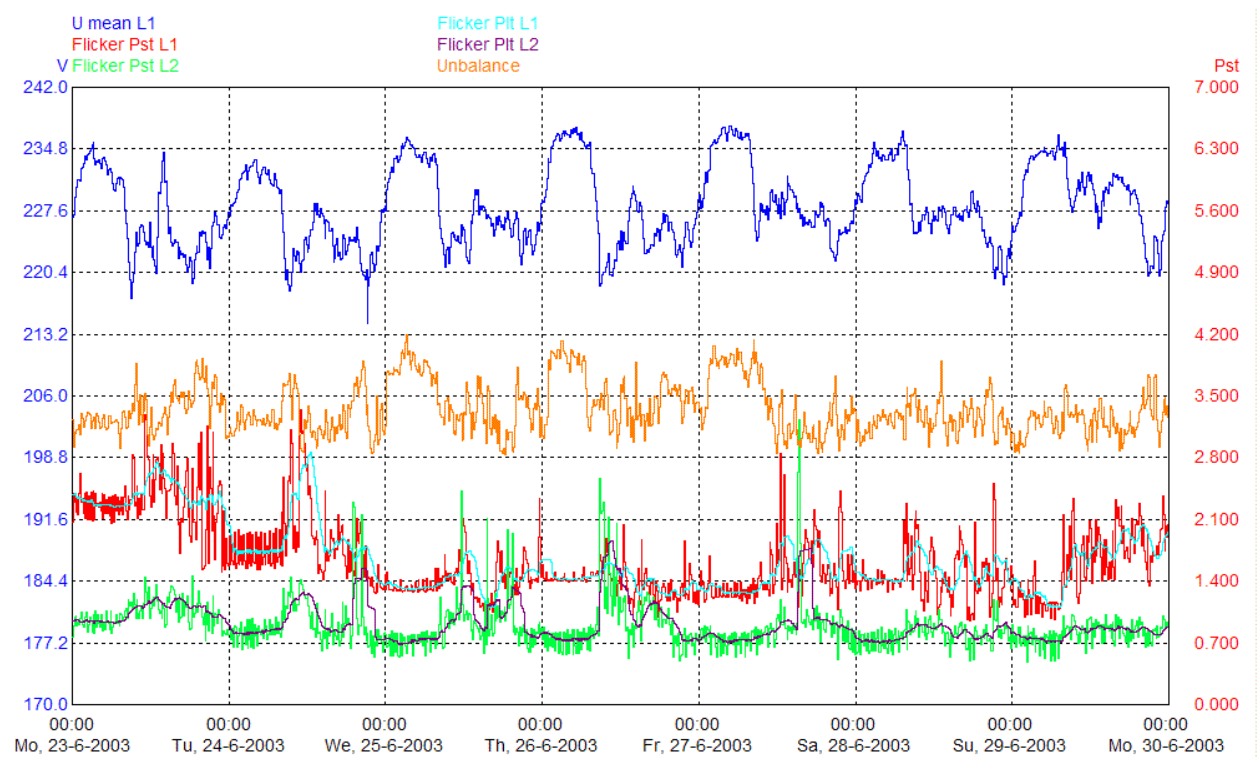

Fig. 5. Several power quality parameters measured at the restaurant over 1 week

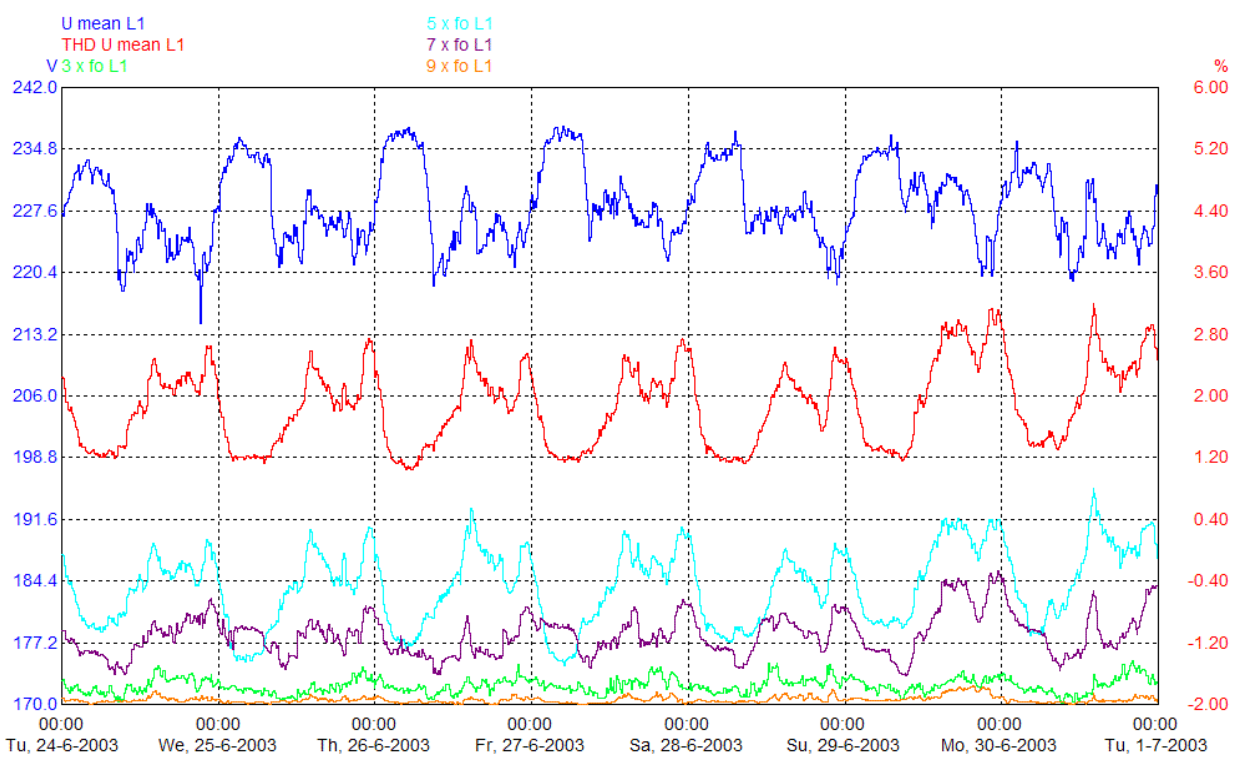

Fig. 6. Several other power quality parameters measured at the restaurant over 1 week

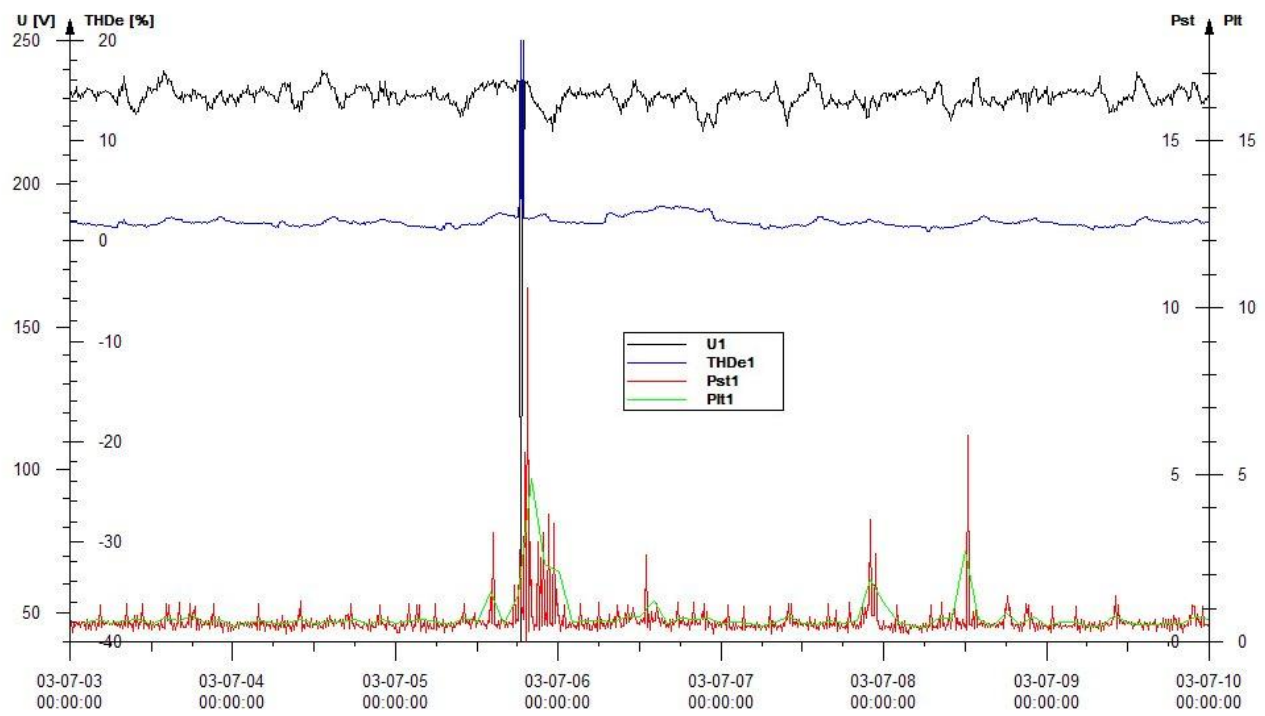

Fig. 7. Some power quality parameters measured at the domestic residence over 1 week 